\title{
Article \\ Interface Asymmetry Induced and Surface Pressure Controlled Valence Tautomerism in Monolayers of bis-Phthalocyaninates of Lanthanides
}

\author{
Daria S. Kutsybala ${ }^{1}$, Alexander V. Shokurov ${ }^{1,2}$, Alexander G. Martynov ${ }^{1}$, Alexey V. Yagodin ${ }^{1}$, \\ Vladimir V. Arslanov ${ }^{1}$, Yulia G. Gorbunova ${ }^{1,3, *(D)}$ and Sofiya L. Selektor ${ }^{1, *}$
}

Citation: Kutsybala, D.S.; Shokurov, A.V.; Martynov, A.G.; Yagodin, A.V.; Arslanov, V.V.; Gorbunova, Y.G.; Selektor, S.L. Interface Asymmetry Induced and Surface Pressure Controlled Valence Tautomerism in Monolayers of bis-Phthalocyaninates of Lanthanides. Symmetry 2022, 14, 340. https://doi.org/10.3390/ sym 14020340

Academic Editors: György Keglevich, Marek Szafrański and Enrico Bodo

Received: 18 December 2021

Accepted: 28 January 2022

Published: 7 February 2022

Publisher's Note: MDPI stays neutral with regard to jurisdictional claims in published maps and institutional affiliations.

Copyright: (C) 2022 by the authors. Licensee MDPI, Basel, Switzerland. This article is an open access article distributed under the terms and conditions of the Creative Commons Attribution (CC BY) license (https:// creativecommons.org/licenses/by/ $4.0 /)$.
1 Frumkin Institute of Physical Chemistry and Electrochemistry of Russian Academy of Sciences, Leninsky pr. 31-4, 119071 Moscow, Russia; dariakutsybala@gmail.com (D.S.K.); shokurov@phyche.ac.ru (A.V.S.); martynov.alexandre@gmail.com (A.G.M.); al.yagodin@mail.ru (A.V.Y.); vladimir.arslanov@gmail.com (V.V.A.)

2 Enikolopov Institute of Synthetic Polymeric Materials of Russian Academy of Sciences, Profsoyuznaya 70, 117393 Moscow, Russia

3 Kurnakov Institute of General and Inorganic Chemistry of Russian Academy of Sciences, Leninsky pr. 31, 119991 Moscow, Russia

* Correspondence: yulia@igic.ras.ru (Y.G.G.); selektor@phyche.ac.ru (S.L.S.)

\begin{abstract}
Supramolecular systems based on transition metal complexes capable of reversible redox isomerization due to intramolecular electron transfer are one of the most interesting objects from the viewpoint of molecular switches' design. In the present work, a comparative analysis of valence transformation of lanthanide complexes $(\mathrm{Sm}, \mathrm{Er}, \mathrm{Tm}$ and $\mathrm{Yb}$ ) with donor-substituted bis-phthalocyaninates occurring during the formation and compression-extension of Langmuir monolayers was carried out using data of UV-Vis-NIR spectroscopy. It is shown that the numerical values of the Q-band positions in the absorption spectra for the extended monolayers of the complexes under study depend linearly on the ionic radius of the metal center, if the metals have an oxidation state of +2 . This makes it possible to draw a direct analogy between the behavior of the studied compounds and analogous europium and cerium complexes, for which direct evidence of the valence tautomerism in such planar systems was obtained earlier. This led to the conclusion that the intramolecular electron transfer from the phthalocyanine ligand to the central metal ion $\left[\mathrm{Ln}^{3+}\left(\mathrm{R}_{4} \mathrm{Pc}^{2-}\right)\left(\mathrm{R}_{4} \mathrm{Pc}^{\bullet-}\right)\right]^{0} \rightarrow\left[\mathrm{Ln}^{2+}\left(\mathrm{R}_{4} \mathrm{Pc}^{\bullet-}\right)_{2}\right]^{0}$ occurs when solutions of donor-substituted bis-phthalocyaninates of samarium, erbium, thulium, and ytterbium are deposited onto the water subphase, and the reverse redox-isomeric transition is observed in most cases when the monolayer is compressed to high surface pressures. The first of these switches is related to the asymmetry of the air/water interface, and the second one is controlled by the lateral compression-expansion of the monolayer. It has been demonstrated that when bisphthalocyanine monolayers of lanthanides with variable valence are transferred to solid substrates, the valence state of the metal center, and consequently, the redox-isomeric state of the complex, do not change. This means that we are able to form films with a predetermined state of the complex. Note that the redox-isomeric state of complexes should affect the entire range of physicochemical properties of such films.
\end{abstract}

Keywords: valence tautomerism; redox isomerism; phase transition; symmetry; thermodynamics; lanthanide; phthalocyanine; monolayer; UV-Vis-NIR spectroscopy

\section{Introduction}

The design of "smart" materials based on molecular switches seems to be a promising step towards the miniaturization of electronics components and the creation of new functional materials. At present, under the impact of the miniaturization idea, new types of molecular devices are being actively studied and elaborated [1-6]. From these standpoints, 
supramolecular systems based on transition metal complexes with redox-active ligands, which are capable of reversible redox-isomer switching due to intramolecular electron transfer, become one of the most interesting objects [7-9]. Such switches are commonly regarded as a special case of valence tautomerism.

Currently, the most studied factors capable of inducing the redox isomerization of chemical compounds are changes in the ambient conditions in the solution (solvent composition) [10-12], thermal [13], and photophysical actions [14], as well as X-ray irradiation [15]. In some cases, the phenomenon of valence tautomerism was detected for single crystals of certain compounds when an external pressure was applied [16-18]. Nevertheless, while the effect of pressure on the processes of redox isomerization is mentioned in the literature for bulk samples [16-18], for surface/interfacial systems this issue remains poorly investigated. Meanwhile, the intrinsically asymmetric nature of air/water and air/solid interfaces often enables processes which can be almost impossible in bulk media [19,20].

It should be noted that, although one can find several works devoted to the phenomena of valence tautomerism at the interface [14,21], they consider only the intramolecular electron transfer induced by light irradiation in the visible range. The observation of redox-isomer transformations in two-dimensional systems at the interface under the influence of transition from homogeneous bulk solution volume to the asymmetric 2D environment of the interface, as well as lateral compression, was first demonstrated in the works of our group on examples of crown-substituted bis-phthalocyaninates of cerium $\mathrm{Ce}\left[(15 \mathrm{C} 5)_{4} \mathrm{Pc}\right]_{2}[22]$ and europium $\mathrm{Eu}\left[(\mathrm{BuO})_{8} \mathrm{Pc}\right]_{2}[23]$ (Figure 1).

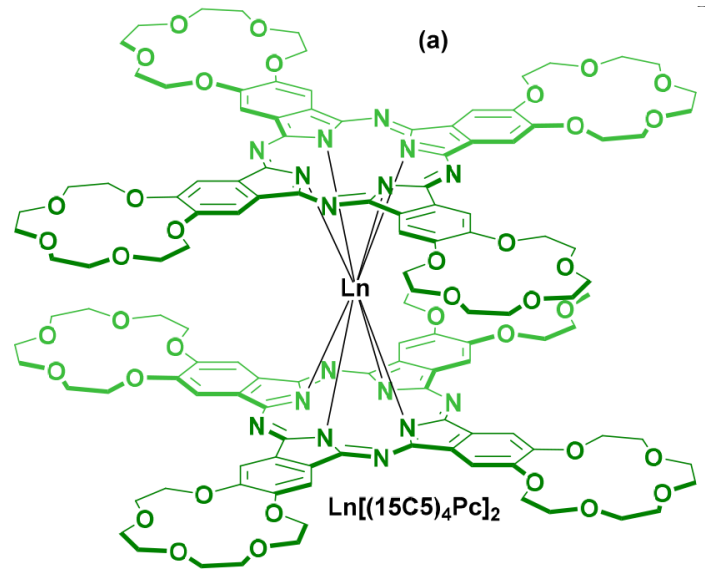

(b)

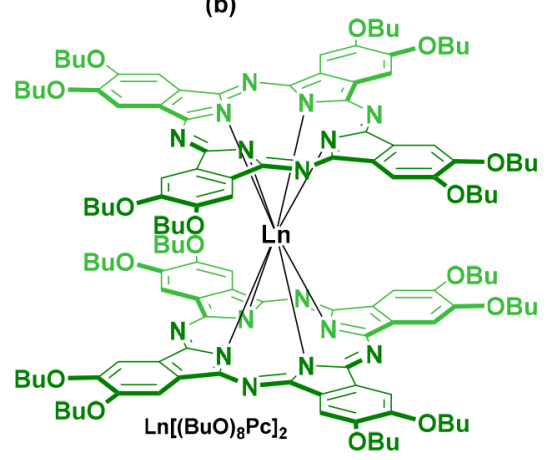

Figure 1. (a) Tetra-15-crown-5-substituted lanthanide bis-phthalocyaninates, $\operatorname{Ln}\left[(15 \mathrm{C} 5)_{4} \mathrm{Pc}\right]_{2}$, $\mathrm{Ln}=\mathrm{Ce}$ [22], Sm (this work); (b) Octa- $n$-butoxysubstituted lanthanide bis-phthalocyaninates $\mathrm{Ln}=\mathrm{Eu}[23]$ and Sm, Er, Tm, Yb (this work).

Thus, in the research works devoted to the study of this process on the example of sandwich-substituted cerium bis-phthalocyaninate [22], it was revealed that intramolecular electron transfer from the ligand to the lanthanide metal center and back (Figure 2a), i.e., reversible redox isomerization of the complex involving the multivalent $\mathrm{Ce}^{3+/ 4+}$ cation, occurs when its solution is deposited on the water surface $\left(\mathrm{Ce}^{4+} \rightarrow \mathrm{Ce}^{3+}\right)$, and the subsequent compression of the thus obtained monolayer results in the reverse transition [13,22,24-27]. Similar $\mathrm{Eu}^{3+} \leftrightarrow \mathrm{Eu}^{2+}$ transitions for monolayers of donor-substituted europium bis-phthalocyaninates were described and unambiguously proved [23] (Figure 2b). 

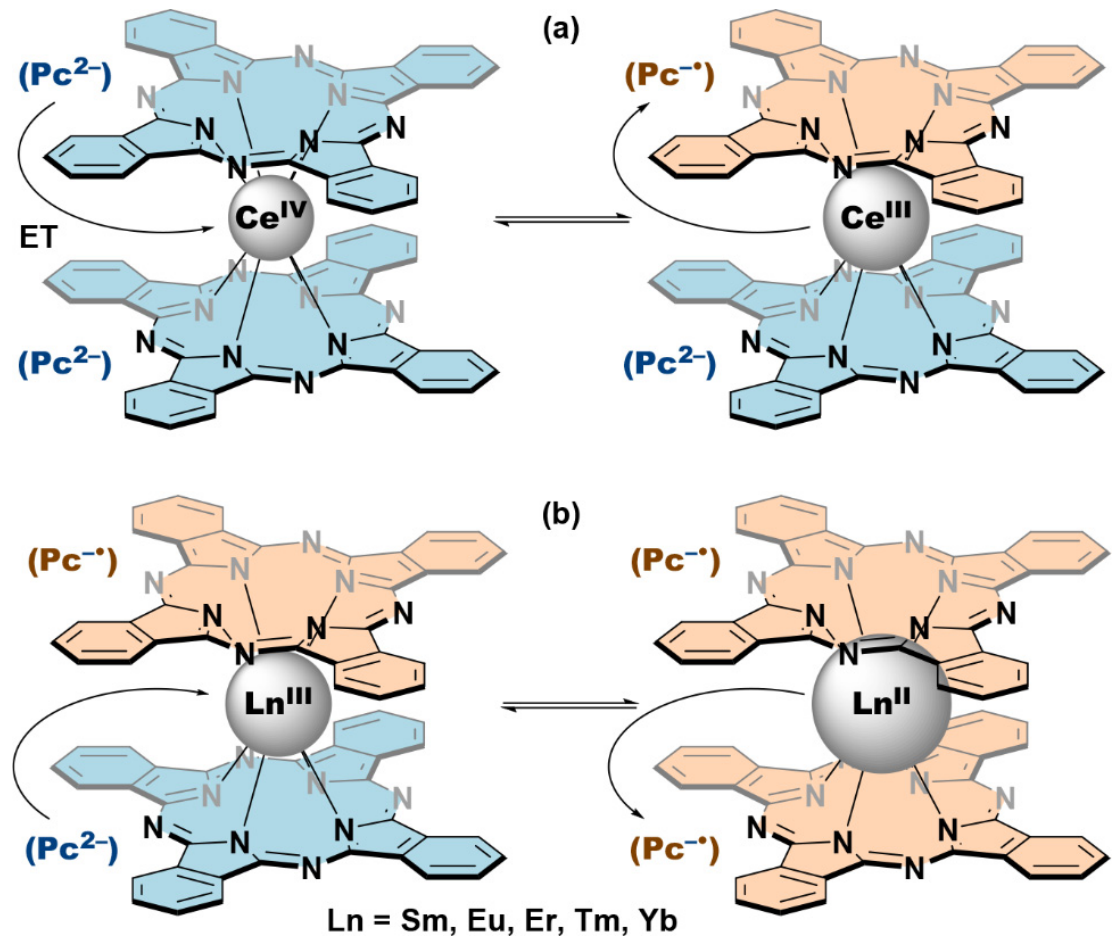

Figure 2. (a) Intramolecular electron transfer (ET) responsible for redox isomerism in cerium(IV/III) bis-phthalocyaninates [22] and (b) in lanthanide(III/II) bis-phthalocyaninates, Ln = Eu [23] and Sm, $\mathrm{Er}, \mathrm{Tm}, \mathrm{Yb}$ (this work). Crown and butoxy substituents are omitted for clarity.

The europium bis-phthalocyaninates, as well as most of trivalent lanthanide bisphthalocyaninates, in bulk solutions exist in neutral forms, where one macrocyclic ligand is in a formal dianionic state and another one is anion-radical- $\left[\left(\mathrm{Pc}^{2-}\right) \mathrm{Ln}^{3+}\left(\mathrm{Pc}^{-} \bullet\right]^{0}\right.$. In symmetrical environments, the unpaired electron is actually delocalized over the Pc $\pi$ system, while the lanthanide ion does not participate in such delocalization [28]. However, specific asymmetrical media at the air/water interface afford more diversity in terms of electronic states.

Until recently, the phenomenon of redox isomerization in 2D supramolecular systems could be registered only indirectly using spectral and electrochemical methods of analysis that register the electronic state of phthalocyanine ligands, which circumstantially indicates the valence state of the metal center. However, the results obtained for $\mathrm{Ce}\left[(15 \mathrm{C} 5)_{4} \mathrm{Pc}\right]_{2}$ and $\mathrm{Eu}\left[(\mathrm{BuO})_{8} \mathrm{Pc}_{2}\right.$ complexes by X-ray absorption near edge spectroscopy (XANES) provide strong evidence that the redox-isomeric switching occurs, and prove the existence of two stable redox states of cerium and europium cations in ultrathin films of their bisphthalocyaninates $[23,29]$.

The proved redox-isomerization process in the monolayers of donor-substituted sandwich cerium and europium phthalocyaninates prompts us to pay attention to similar double-decker phthalocyanine complexes with other elements of the lanthanide series, and this work is devoted to this subject on the examples of $\mathrm{Sm}, \mathrm{Er}, \mathrm{Tm}$ and $\mathrm{Yb}$ derivatives. Excellent agreement of X-ray and absorbance data for phthalocyaninates in different redox-isomeric states makes it possible to draw unambiguous conclusions on valence changes occurring within the lanthanide bis-phthalocyaninates monolayers using in situ optical spectroscopy.

\section{Materials and Methods}

\subsection{Physical-Chemical Measurements}

UV-Vis-NIR spectra in chloroform solution were measured using a spectrophotometer V-770 (JASCO) in quartz cells with $1 \mathrm{~cm}$ optical path. Matrix-assisted laser desorption ionization time-of-flight (MALDI-TOF) mass spectra were measured on a Bruker Daltonics 
Ultraflex spectrometer. Mass spectra were registered in positive ion mode using 2,5dihydroxybenzoic acid as a matrix. MALDI-TOF mass spectra of synthesized complexes are provided in Supplementary Information.

Langmuir monolayers were obtained using KSV Minitrough (Finland) with a trough area of $273.0 \mathrm{~cm}^{2}$ and Kibron Microtrough G2 with a trough area of $280 \mathrm{~cm}^{2}$. Both troughs were made of a chemically inert material-Teflon-which prevents possible leakage of subphase, and barriers were made of hydrophilic polyacetal. The solution of the studied metal complex with a concentration of $1-1.5 \times 10^{-5} \mathrm{M}$ in $\mathrm{CHCl}_{3}$ was deposited onto the subphase surface using the glass chromatographic syringe with a nominal volume of $1000 \mu \mathrm{L}$. The monolayer was left undisturbed for $20 \mathrm{~min}$ for complete evaporation of the solvent from the subphase surface and then compressed using automated movable barriers at the speed of $5 \mathrm{~mm} / \mathrm{min}$. Langmuir monolayers were transferred onto the quartz plates $(2 \times 1 \mathrm{~cm})$ using the Langmuir-Blodgett technique (vertical transfer). All investigated films were single layered.

UV-Vis absorption spectra of monolayers of crown- and butoxysubstituted lanthanide bis-phthalocyaninates on the aqueous subphase were recorded in the $370-800 \mathrm{~nm}$ wavelength range using an AvaSpec-2048 fiber optic spectrophotometer equipped with an AvaLight HAL (Avantes, The Netherlands) halogen light source. According to the previously described technique [30], a reflectometric probe with a fiber diameter of $400 \mu \mathrm{m}$ in combination with a six-fiber emitting cable was placed perpendicular to the subphase surface at a distance of $2-3 \mathrm{~mm}$ from the monolayer. The signal obtained by light reflection from the surface of the aqueous subphase just before the monolayer spreading was used as a baseline.

All experiments were carried out under ambient conditions: air atmosphere, air and subphase temperature of $20 \pm 1{ }^{\circ} \mathrm{C}$.

\subsection{Synthesis and Characterization of Phthalocyanines}

Starting phthalocyanine ligands- $\mathrm{H}_{2}\left[(\mathrm{BuO})_{8} \mathrm{Pc}\right]$ and $\mathrm{H}_{2}\left[(15 \mathrm{C} 5)_{4} \mathrm{Pc}\right]$ - were synthesized using the previously reported methods from corresponding phthalonitriles [31]. Chloroform for chromatography and spectral measurements was distilled over $\mathrm{CaH}_{2} \cdot 1$,8diazabicyclo[5.4.0] undec-7-ene was distilled over $\mathrm{CaH}_{2}$ in vacuum and stored under argon. All other reagents were used as received from commercial suppliers.

General procedure for the preparation of lanthanide(III) bis(octa-n-butoxyphthalocyaninates) on the example of $\mathrm{Sm}\left[(\mathrm{BuO})_{8} \mathrm{Pc}_{2}\right.$ : Metal-free ligand $\mathrm{H}_{2}\left[(\mathrm{BuO})_{8} \mathrm{Pc}\right](29.5 \mathrm{mg}, 27 \mu \mathrm{mol})$ was suspended in 1-chloronaphthalene $(2 \mathrm{~mL})$ and 1-octanol $(1 \mathrm{~mL})$. DBU $(123 \mathrm{mg}, 0.81 \mathrm{mmol})$ was added and the mixture was brought to reflux under flow of argon. Samarium(III) acetate tetrahydrate $(16.2 \mathrm{mg}, 41 \mu \mathrm{mol})$ was added. Reflux was continued for $1 \mathrm{~h} 10 \mathrm{~min}$ until disappearance of $Q$ bands of the starting ligand at 660 and $700 \mathrm{~nm}$ in UV-Vis spectra of reaction mixture samples in chloroform. After cooling to room temperature, methanol was added, the formed precipitate was filtered, washed off the filter with chloroform and applied to a chromatographic column packed with neutral alumina in a mixture of chloroform and hexane ( $3 \mathrm{~V}: 2 \mathrm{~V})$. The complex was eluted with the same mixture of solvents and additionally purified by size exclusion chromatography on Bio-Beads SX-1 sorbent using chloroform with $2.5 \mathrm{vol} . \%$ methanol. The complex was isolated as a dark-green solid, with a yield of $21.6 \mathrm{mg}(69 \%)$. Other complexes were synthesized in $65-78 \%$ yields using the same procedure.

$\mathrm{Sm}\left[(\mathrm{BuO})_{8} \mathrm{Pc}\right]_{2}$ : MALDI-TOF MS $(\mathrm{m} / \mathrm{z}) 2331.1[\mathrm{M}]^{+}\left(2331.1\right.$ calculated for $\left.\mathrm{C}_{128} \mathrm{H}_{160} \mathrm{~N}_{16} \mathrm{O}_{16} \mathrm{Sm}\right)$. UV-Vis-NIR (CHCl $) \lambda_{\max }(\mathrm{nm})(\log \varepsilon): 293$ (5.02), 339 (4.99), 372 (5.04), 494 (4.60), 616 (4.50), 681 (5.12), 909 (3.53), 1675 (4.08).

$\mathrm{Er}\left[(\mathrm{BuO})_{8} \mathrm{Pc}\right]_{2}$ : MALDI-TOF MS $(\mathrm{m} / \mathrm{z}) 2345.2[\mathrm{M}]^{+}\left(2345.2\right.$ calculated for $\left.\mathrm{C}_{128} \mathrm{H}_{160} \mathrm{ErN}_{16} \mathrm{O}_{16}\right)$. UV-Vis-NIR ( $\left.\mathrm{CHCl}_{3}\right) \lambda_{\max }(\mathrm{nm})(\log \varepsilon): 293$ (5.18), 369 (5.27), 482 (4.76), 607 (4.66), 672 (5.35), 914 (3.91), 1428 (4.31), 1562 (4.29). 
$\operatorname{Tm}\left[(\mathrm{BuO})_{8} \mathrm{Pc}\right]_{2}$ : MALDI-TOF MS $(m / z) 2346.3[\mathrm{M}-\mathrm{H}]^{+}\left(2347.2\right.$ calculated for $\left.\mathrm{C}_{128} \mathrm{H}_{160} \mathrm{~N}_{16} \mathrm{O}_{16} \mathrm{Tm}\right)$. UV-Vis-NIR $\left(\mathrm{CHCl}_{3}\right) \lambda_{\max }(\mathrm{nm})(\log \varepsilon): 292$ (5.08), 369 (5.20), 481 (4.67), 607 (4.56), 671 (5.27), 916 (3.87), 1425 (4.26), 1552 (4.10).

$\mathrm{Yb}\left[(\mathrm{BuO})_{8} \mathrm{Pc}\right]_{2}:$ MALDI-TOF MS $(\mathrm{m} / z) 2350.4[\mathrm{M}-\mathrm{H}]^{+}\left(2351.2\right.$ calculated for $\left.\mathrm{C}_{128} \mathrm{H}_{160} \mathrm{~N}_{16} \mathrm{O}_{16} \mathrm{Tm}\right)$. UV-Vis-NIR $\left(\mathrm{CHCl}_{3}\right) \lambda_{\max }(\mathrm{nm})(\log \varepsilon): 292$ (4.79), 369 (4.90), 479 (4.38), 606 (4.28), 670 (4.99), 917 (3.56), 1418 (3.97), 1540 (3.87).

Synthesis of samarium(III) bis(tetra-15-crown-5-phthalocyaninate): Metal-free ligand $\mathrm{H}_{2}\left[(15 \mathrm{C} 5)_{4} \mathrm{Pc}\right]$ (35 mg, $27 \mu \mathrm{mol}$ ) was suspended in 1-chloronaphthalene $(2 \mathrm{~mL})$ and 1-octanol $(1 \mathrm{~mL}), \mathrm{DBU}$ (125 mg, $0.82 \mathrm{mmol}$ ) was added, mixture was brought to reflux under flow of argon, and samarium(III) acetate tetrahydrate $(17 \mathrm{mg}, 41 \mu \mathrm{mol})$ was added. Reflux was continued for $45 \mathrm{~min}$ until disappearance of $Q$ bands of the starting ligand at 660 and $700 \mathrm{~nm}$ in UV-Vis spectra of reaction mixture samples in chloroform. After cooling to room temperature, $50 \mathrm{~mL}$ of mixture of hexane and ethylacetate ( $3 \mathrm{~V}: 2 \mathrm{~V}$ ) was added, the formed precipitate was filtered, washed off the filter with chloroform and the resulting solution was treated with manganese(IV) dioxide under sonication for $10 \mathrm{~min}$. Resulting slurry was transferred to a chromatographic column packed with alumina in chloroform. Elution with chloroform with $1.5 \mathrm{vol} . \%$ methanol with additional purification by size exclusion chromatography on Bio-Beads SX-1 sorbent, using chloroform with $2.5 \mathrm{vol}$ \% methanol, afforded the target complex as a dark-green solid. Yield was $27 \mathrm{mg}$ (72\%). $\mathrm{Sm}\left[(15 \mathrm{C} 5)_{4} \mathrm{Pc}\right]_{2}$ : MALDI-TOF MS $(\mathrm{m} / z) 2698.9[\mathrm{M}]^{+}\left(2698.9\right.$ calculated for $\left.\mathrm{C}_{128} \mathrm{H}_{144} \mathrm{~N}_{16} \mathrm{O}_{40} \mathrm{Sm}\right)$. UV-Vis-NIR $\left(\mathrm{CHCl}_{3}\right) \lambda_{\max }(\mathrm{nm})(\log \varepsilon): 292$ (4.96), 338 (4.95), 372 (5.00), 493 (4.55), 613 (4.46), 678 (5.10), 906 (3.52), 1698 (3.99).

\section{Results}

Target bis-phthalocyaninates were synthesized using direct metalation of butoxyor crown-substituted phthalocyanines with lanthanide acetates in the presence of 1,8 diazabicyclo [5.4.0] undec-7-ene (DBU) as a deprotonating agent, which facilitates formation of double-decker complexes [32]. Using a mixture of 1-chloronaphthalene and 1-octanol $(2 \mathrm{~V}: 1 \mathrm{~V})$ was found to be beneficial for the synthesis of complexes. This reduced reaction time and increased the yield of the target complexes compared to each of the pure solvents previously used for similar reactions $[33,34]$. Complexes were characterized by MALDITOF mass spectrometry, and the observed $m / z$ values and isotopic distribution patterns of molecular ions were in good agreement with theoretically predicted spectra (Figures S1-S5), confirming the composition of synthesized compounds.

UV-Vis-NIR spectra of the studied complexes have typical features for neutral bisphthalocyaninates of trivalent lanthanides (Figure 3). While the N (290 nm), Soret or B (300-400 nm) and Q (670-680 nm) bands are typical for phthalocyanines in general, the additional absorbances at 480-490 (blue valence bands, BV), 910-920 (red valence bands, RV) and 1400-1600 nm (intervalence bands, IV) are characteristics of double-decker complexes containing one unpaired electron $[28,35,36]$. The positions of all bands in the spectra of series of complexes gradually shift following the decrease in lanthanide ions radius causing the increase in intramolecular $\pi-\pi$ interaction [37].

Of note, the natures of either crown or butoxy substituents have only a minor effect on the positions of bands in UV-Vis-NIR spectra, as shown in the examples of samarium(III) complexes (Figure 3a).

Figure 4 shows that for butoxy-substituted complexes of trivalent lanthanides in chloroform solution, the experimental values of both the Q-band and BV-band positions in the UV-Vis absorption spectra are related to the ionic radius of the lanthanide metal center by the linear correlations (Pearson's $r=0.995$ in both cases), which is similar to that obtained for crown-substituted bis-phthalocyaninates [22]. This fact indicates that the lanthanide ions are in the trivalent state in all the studied complexes in solution.

Based on our previous studies of the redox transformations of the sandwich cerium crown phthalocyaninate and analogous crown- and butoxy-substituted europium complexes [22,23], we chose the formation conditions and obtained Langmuir monolayers of butoxy- and crown-substituted bis-phthalocyaninates of $\mathrm{Yb}, \mathrm{Sm}, \mathrm{Er}$, and $\mathrm{Tm}$ at the 
air/water interface in the present work. Monolayers were obtained by spreading the corresponding compounds' chloroform solutions onto the aqueous subphase according to the procedure described in the experimental section. As an example, Figure 5 shows compression isotherms of monolayers of $\mathrm{Yb}\left[(\mathrm{BuO})_{8} \mathrm{Pc}\right]_{2}$ and $\mathrm{Sm}\left[(\mathrm{BuO})_{8} \mathrm{Pc}_{2}\right.$ complexes, and the previously described [23] compression isotherm of $\mathrm{Eu}\left[(\mathrm{BuO})_{8} \mathrm{Pc}\right]_{2}$ monolayer is shown for comparison.

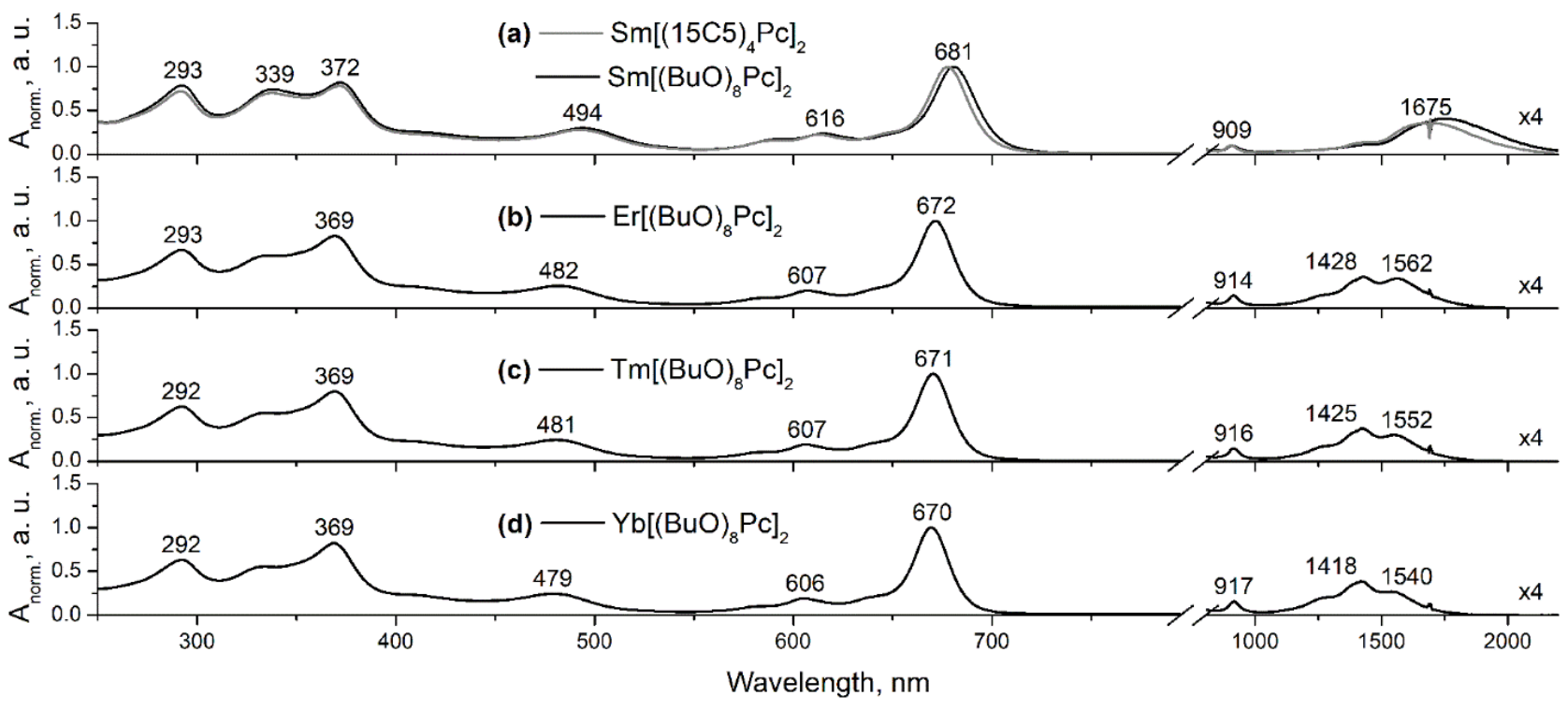

Figure 3. UV-Vis-NIR spectra of $\operatorname{Ln}\left[(15 \mathrm{C} 5)_{4} \mathrm{Pc}\right]_{2}$ and $\operatorname{Ln}\left[(\mathrm{BuO})_{8} \mathrm{Pc}\right]_{2}, \mathrm{Ln}=(\mathbf{a}) \mathrm{Sm},(\mathbf{b}) \mathrm{Er},(\mathbf{c}) \mathrm{Tm}$ and (d) $\mathrm{Yb}$ in chloroform. The band intensities in the NIR range are increased by a factor of four.
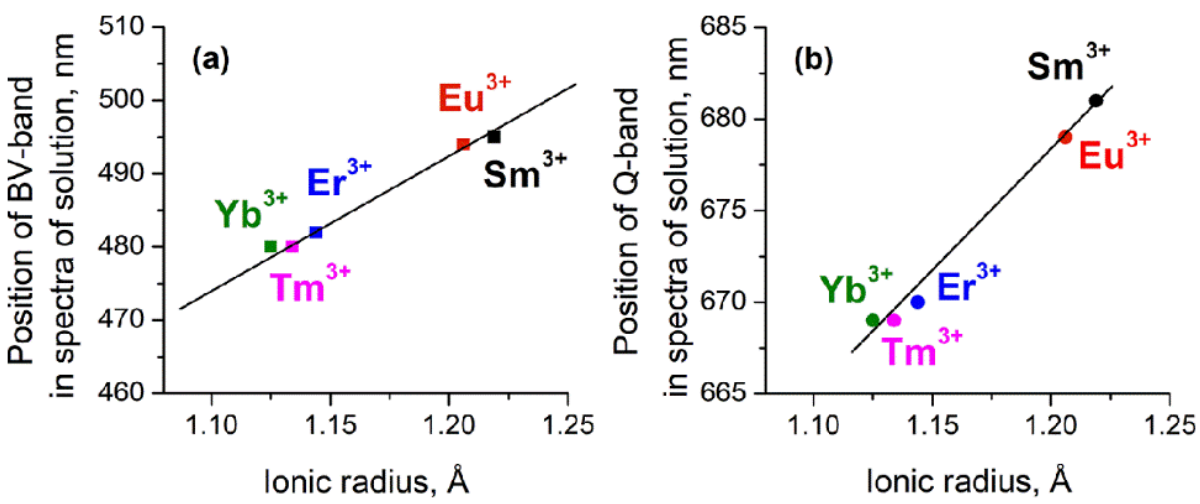

Figure 4. Position of the BV band (a) and Q band (b) in the spectra of the studied lanthanide octa- $n$ butoxybis-phthalocyaninates in chloroform as a function of the complex metal center ionic radius.

For the compounds under study, the mean molecular area that corresponds to the start of surface pressure growth varies from 440 to $490 \AA^{2}$ for complexes of different metals. These values allow us to assume a face-on orientation of the molecules in the expanded monolayer.

Spectral measurements were performed in parallel with the recording of the monolayer compression isotherms. It should be emphasized that for all the compounds under consideration, an unusual evolution of the spectra of the monolayers during formation and compression was observed. In general, the spectral changes recorded have a similar nature, although some specific features can be distinguished for each complex. In particular, as in the case of the previously described butoxysubstituted europium bis-phthalocyaninate [23], when the chloroform solution of the analogous ytterbium complex is deposited onto the water subphase surface during the solvent evaporation, the compound UV-vis absorption 
spectrum changes markedly: the shift of the $Q$ band to the longer wavelength region (in this case from 678 to $707 \mathrm{~nm}$ ) and the simultaneous bathochromic shift of the BV band from 480 to $501 \mathrm{~nm}$ are observed (Figure 6).

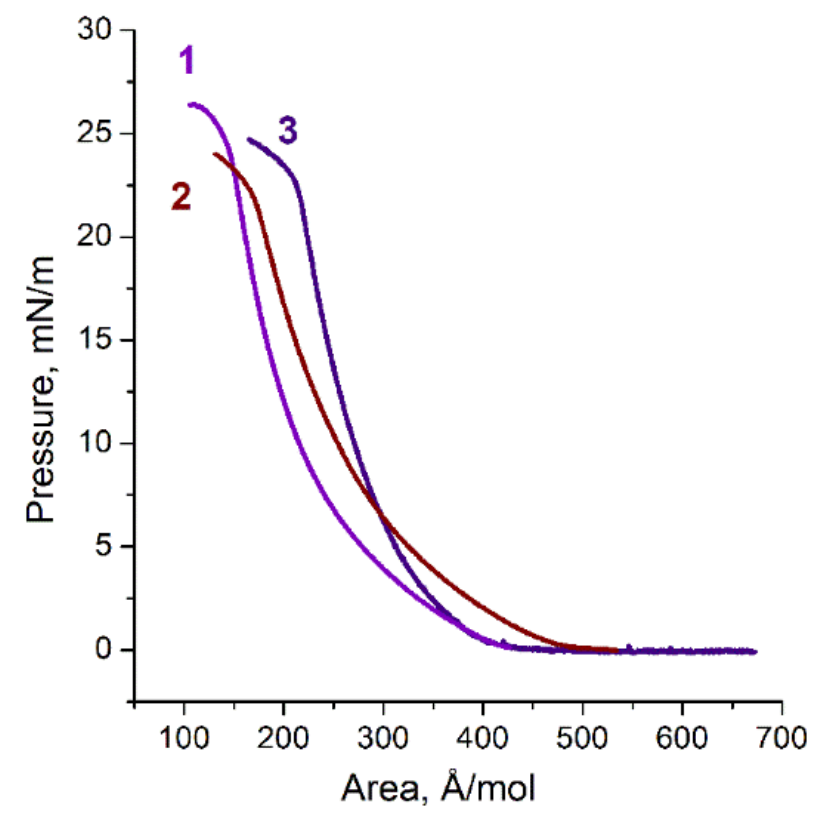

Figure 5. Monolayer compression isotherms of (1) $\mathrm{Yb}\left[(\mathrm{BuO})_{8} \mathrm{Pc}\right]_{2}$, (2) $\mathrm{Eu}\left[(\mathrm{BuO})_{8} \mathrm{Pc}\right]_{2}$ and (3) $\mathrm{Sm}\left[(\mathrm{BuO})_{8} \mathrm{Pc}\right]_{2}$ at the air/water interface.

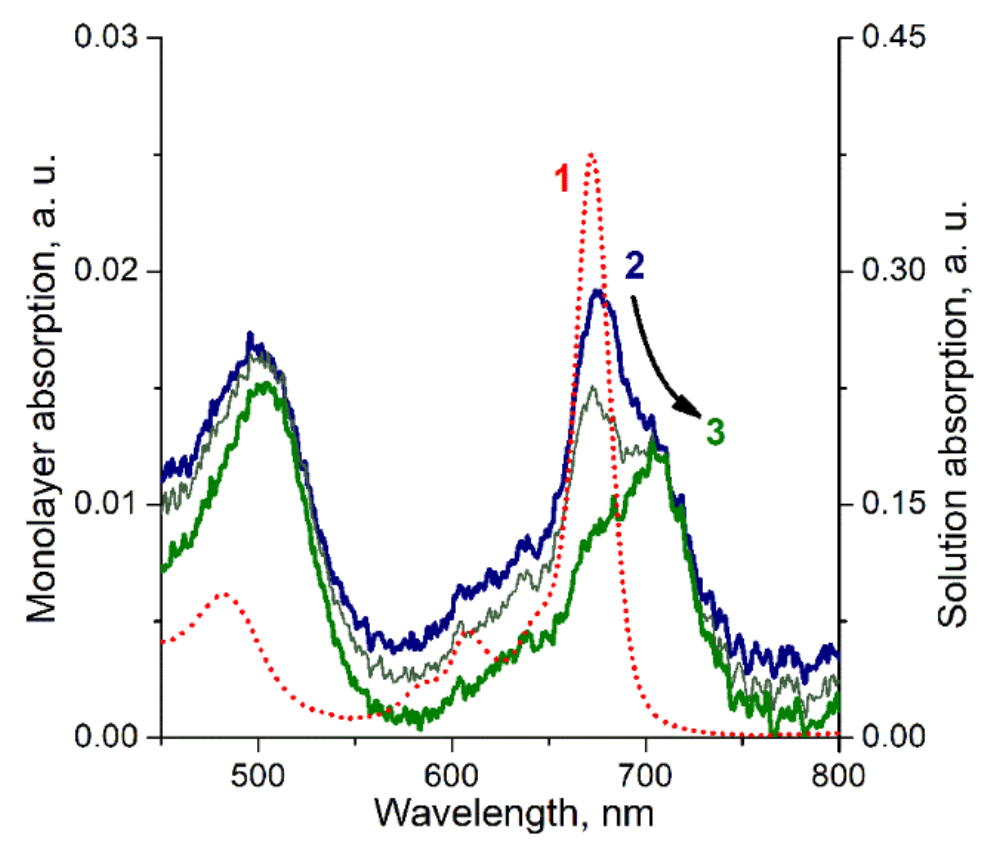

Figure 6. UV-Vis absorbance spectra of $\mathrm{Yb}\left[(\mathrm{BuO})_{8} \mathrm{Pc}\right]_{2}$ in (1) chloroform solution, (2) and (3) monolayer at air/water interface: (2) just after spreading of the solution, and (3) after 20 min of solvent evaporation; the black arrow shows the direction of spectral evolution from state (2) to (3).

During lateral compression of the thus formed monolayer of butoxy-substituted ytterbium bis-phthalocyaninate, an inverse transformation of the spectrum was detected, in which the short-wave component of the $\mathrm{Q}$ band becomes predominant at pressures above $25 \mathrm{mN} / \mathrm{m}$ (Figure 7). 


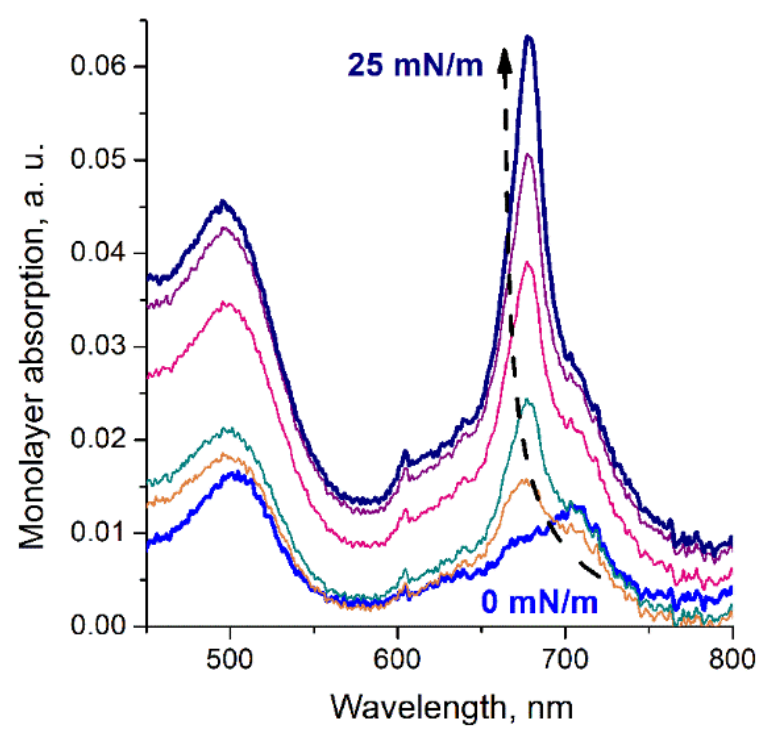

Figure 7. The evolution of the UV-Vis absorbance spectra of $\mathrm{Yb}\left[(\mathrm{BuO})_{8} \mathrm{Pc}\right]_{2}$ monolayer upon lateral compression up to surface pressure of $25 \mathrm{mN} / \mathrm{m}$; the black arrow shows the direction of spectral evolution from blue to navy ones.

The evolution of the monolayer spectra of the crown-substituted samarium complex is somewhat different from that described above (Figure 8). As in the previous case, when a solution of $\mathrm{Sm}\left[(15 \mathrm{C} 5)_{4} \mathrm{Pc}_{2}\right.$ in chloroform is deposited onto the aqueous subphase, a gradual redistribution of the component intensities is observed during solvent evaporation. This spectral behavior of the compound under study, as for the analogous europium complex, can be explained by intramolecular electron transfer from the phthalocyanine ligand to the metal center. Interestingly, similar spectral changes have been observed previously by Rodriguez-Mendez et al. on the example of Langmuir-Blodgett (LB) films of bis[octakis(propyloxy)phthalocyaninate] samarium(III) complex [38]. However, such behavior was described as characteristic of Davydov splitting due to special organization of phthalocyanine molecules in the thin films.

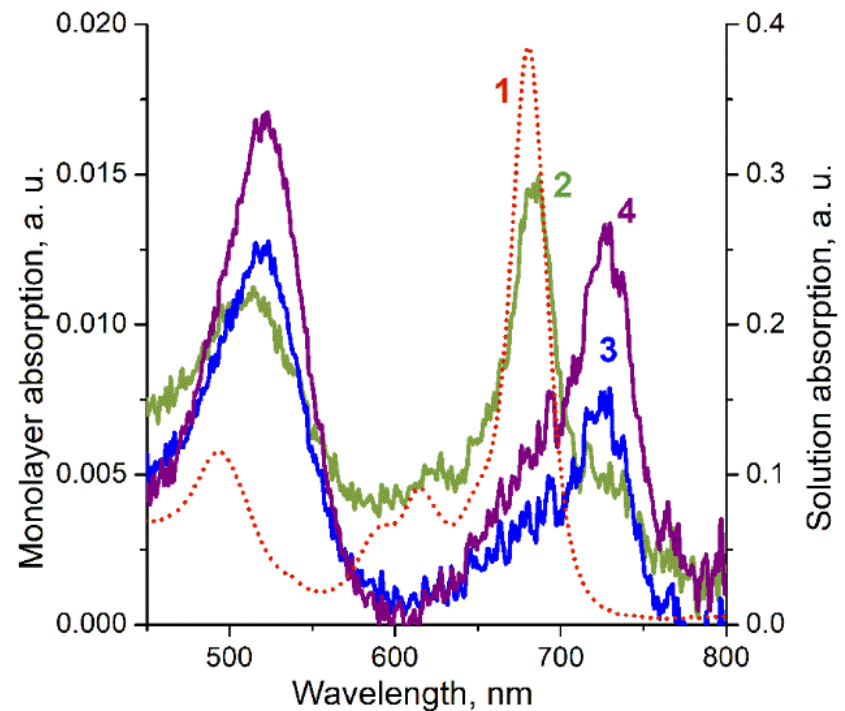

Figure 8. UV-Vis absorbance spectra of $\mathrm{Sm}\left[(15 \mathrm{C} 5)_{4} \mathrm{Pc}_{2}\right.$ in (1) chloroform solution, (2), (3) and (4) monolayer at the air/water interface: (2) just after spreading of the solution, (3) after chloroform evaporation (20 $\mathrm{min}$ ), and (4) upon lateral compression up to surface pressure of $15 \mathrm{mN} / \mathrm{m}$. 
However, unlike the previously studied europium and cerium complexes and the ytterbium complex described above, the lateral compression of the samarium crownsubstituted bis-phthalocyaninate monolayer, even to high values of surface pressure, does not lead to a reverse redox-isomer transition. The replacement of the substituents of the phthalocyanine macrocycle from 15-crown-5 to more donor butoxyl substituents [39] does not cause significant changes in the behavior of this complex upon transition to the interface, and also does not allow for a reverse redox-isomer transition upon monolayer compression.

In the case of $\operatorname{Tm}\left[(\mathrm{BuO})_{8} \mathrm{Pc}\right]_{2}$ and $\operatorname{Er}\left[(\mathrm{BuO})_{8} \mathrm{Pc}\right]_{2}$, the broad peak in the UV-Vis absorption spectra (Figures 9 and 10), which overlaps both components of the $\mathrm{Q}$ band corresponding to the di- and tri-valent states of the metal centers, indicates that the supposed first intramolecular electron transfer at the time of formation of the supramolecular structure at the interface occurs only partially (not in all molecules in the monolayer). Herewith, after compression of thus obtained monolayers, the narrowing and blue shift of the $\mathrm{Q}$ band to the position corresponding to the trivalent state of the metal center is observed.

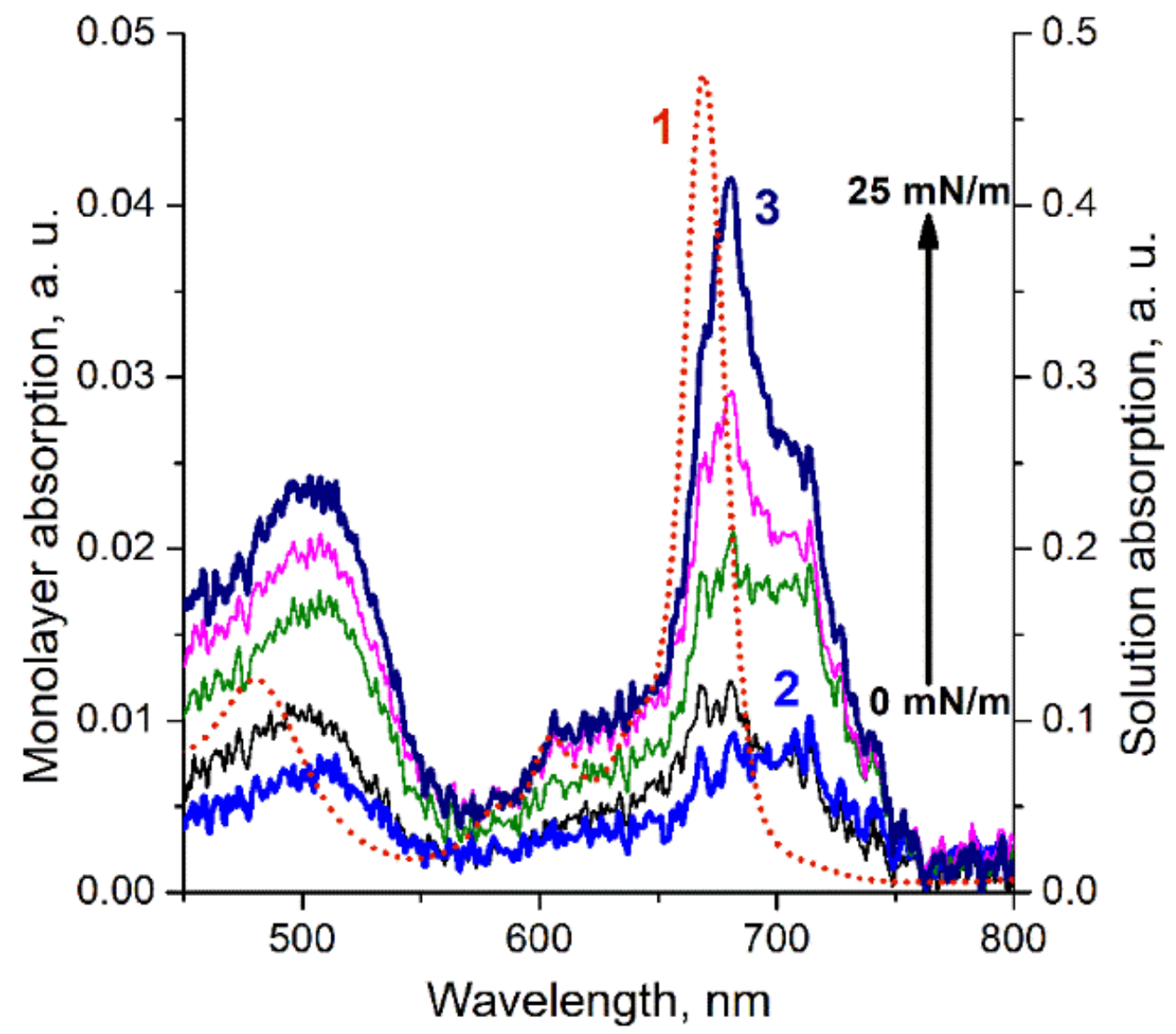

Figure 9. UV-Vis absorbance spectra of $\operatorname{Tm}\left[(\mathrm{BuO})_{8} \mathrm{Pc}\right]_{2}$ in (1) chloroform solution, (2) and (3) monolayer at the air/water interface: (2) just after spreading of the solution, and (3) upon lateral compression up to surface pressure of $25 \mathrm{mN} / \mathrm{m}$, between spectra 2 and 3 the spectra for some intermediate lateral pressures from 0 to $25 \mathrm{mN} / \mathrm{m}$ are presented; the black arrow shows the direction of spectra evolution from state (2) to (3). 


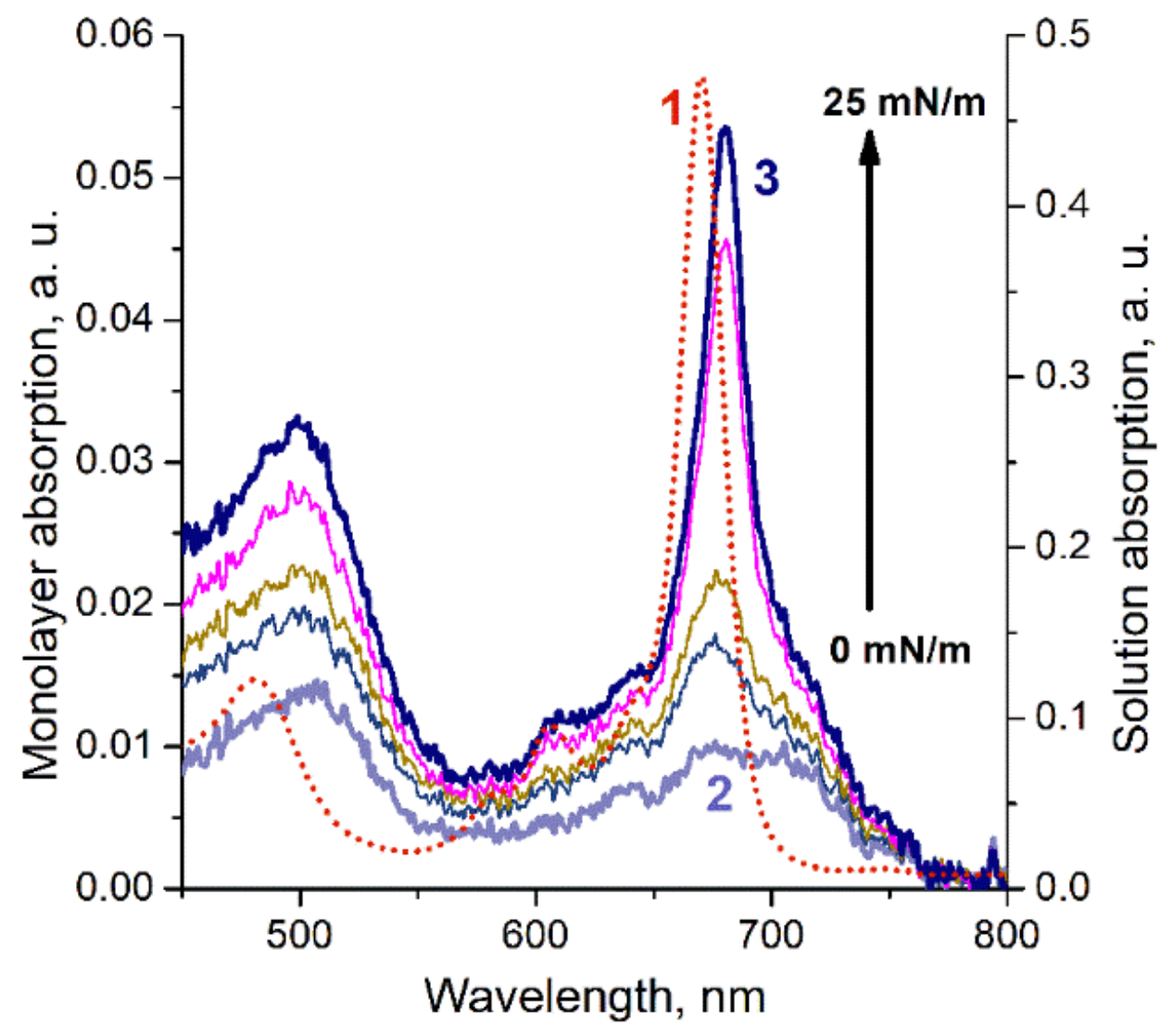

Figure 10. UV-Vis absorbance spectra of $\operatorname{Er}\left[(\mathrm{BuO})_{8} \mathrm{Pc}\right]_{2}$ in (1) chloroform solution, (2) and (3) monolayer at air/water interface: (2) just after spreading of the solution, and (3) upon lateral compression up to surface pressure of $25 \mathrm{mN} / \mathrm{m}$, between spectra 2 and 3 the spectra for some intermediate lateral pressures from 0 to $25 \mathrm{mN} / \mathrm{m}$ are presented; the black arrow shows the direction of spectra evolution from state (2) to (3).

\section{Discussion}

The described changes, by analogy with the changes in the monolayers of cerium and europium donor-substituted bis-phthalocyaninates, can be interpreted as redox-isomeric transformations of the complexes during the transition from solution to the air/water interface and subsequent surface pressure-controlled reversible transitions during monolayer compression-expansion. In other words, we can reasonably assume that when a solution of lanthanide bis-phthalocyaninate is deposited onto the aqueous subphase, an intramolecular electron transfer from the phthalocyanine ligand to the metal $\left[\mathrm{Ln}^{3+}\left(\mathrm{R}_{4} \mathrm{Pc}^{2-}\right)\left(\mathrm{R}_{4} \mathrm{Pc}^{\bullet-}\right)\right]^{0} \rightarrow$ $\left[\mathrm{Ln}^{2+}\left(\mathrm{R}_{4} \mathrm{Pc}^{\bullet-}\right)_{2}\right]^{0}$ occurs (Figure $2 \mathrm{~b}$ ), while the opposite transition is observed in most cases at monolayer compression.

It should be noted that it was shown earlier [22] that for analogous complexes of $\mathrm{Lu}$, for which only the trivalent metal center state is possible, as would be expected, no evolution of the monolayer spectra was observed

The assumption that in all the complexes of metals with variable valence considered in this work, the metal center of the complex changes its valence state upon reaching the interface, agrees well with the results of comparative analysis of the electronic spectra of the monolayers. It was found that the numerical values of Q- and BV-band positions in the absorption spectra of the monolayers of the studied donor-substituted phthalocyanine lanthanide complexes and the divalent europium complex registered immediately after the monolayer formation fit into a straight line in the coordinates (wavelength) - (ion radius of the metal center) (Pearson's $r=0.95$ for both bands) (Figure 11). This can serve as 
additional confirmation that all of the metals in question have an oxidation state of +2 in the extended monolayer.
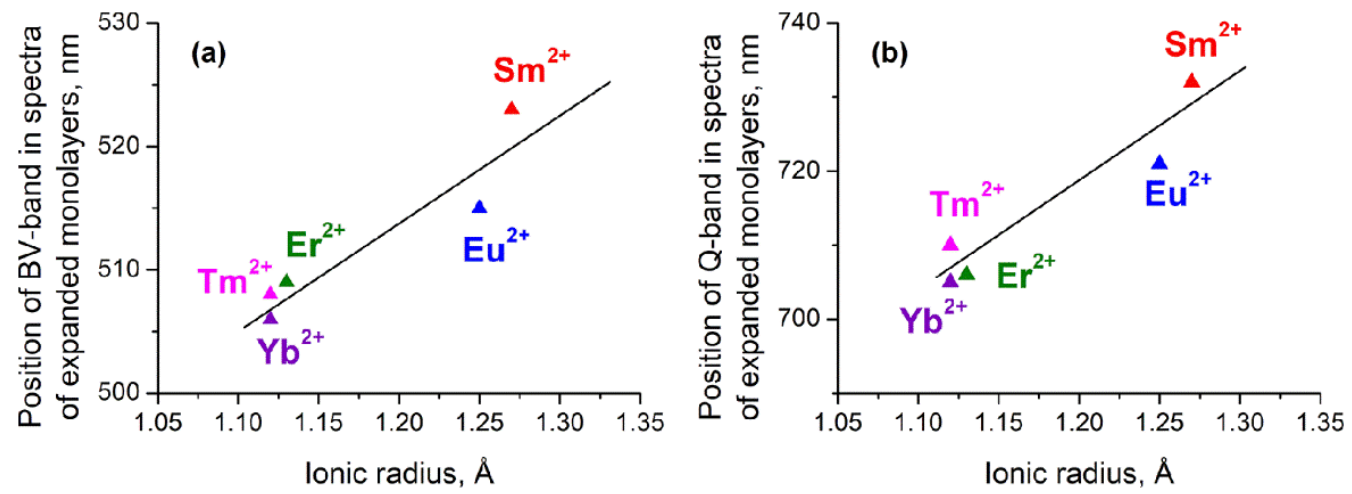

Figure 11. Position of the BV band (a) and Q band (b) in the UV-Vis spectra of expanded monolayers of the studied lanthanide bis-phthalocyaninates as a function of the ionic radius of the complex metal center.

The revealed transformations seem to be related to the breaking of symmetry between the two macroring planes in the sandwich phthalocyanine complexes at the air/water interface, since one of the ligands turns out to be solvated by water in the subphase, while the other one is surrounded by air. Such an asymmetric state facilitates the transfer of one of the electrons from the multielectron ligand to the central metal ion: $\left[\mathrm{Ln}^{3+}\left(\mathrm{R}_{4} \mathrm{Pc}^{2-}\right)\left(\mathrm{R}_{4} \mathrm{Pc}^{\bullet-}\right)\right]^{0} \rightarrow$ $\left[\mathrm{Ln}^{2+}\left(\mathrm{R}_{4} \mathrm{Pc}^{\bullet-}\right)_{2}\right]^{0}$ (i.e., $\left.\mathrm{Ln}^{2+} \rightarrow \mathrm{Ln}^{3+}\right)$. The lateral compression of the $\mathrm{Ln}\left[(\mathrm{BuO})_{8} \mathrm{Pc}\right]_{2}$ monolayer at the air/water interface leads to the reorientation of the discotic molecules to the edge-on position, where both ligands can be considered as equivalent. Moreover, the lateral compression at high surface pressures facilitates the convergence of the ligands within the complex. This, in turn, facilitates intramolecular electron transfer from the metal cation to the phthalocyanine ligand, since an increase in the oxidation state of the metal is accompanied by a decrease in its ionic radius, and consequently, by a decrease in the interdeck distance in the complex [40]. In other words, in absolute accordance with the classical principle of Le Chatelier, compression in the system facilitates the processes that lead to a decrease in its size. As a result, the "extra" electron returns to the ligand and the oxidation state of the metal center is reversed $\mathrm{Ln}^{2+} \rightarrow \mathrm{Ln}^{3+}$.

From the standpoint of this mechanism, the observed differences in the behavior of the studied complexes upon monolayer compression can be explained by the fact that as the ionic radius of the lanthanide cation increases, the interdeck distance in the complex also grows, which makes it more difficult to transfer the electron from the ligand to the metal.

The answer to the question of whether the change in the redox-isomeric state of the complexes under study does not manifest itself upon transition from the solution to the surface of solid substrates was obtained using the ytterbium complex as an example. To do this, $\mathrm{Yb}\left[(\mathrm{BuO})_{8} \mathrm{Pc}\right]_{2}$ cast films with chaotic molecular organization were formed on quartz substrates. The absorption spectra of such films were similar to those of the chloroform solutions of the compounds under study, where the metal center has an oxidation state of +3 (Figure 12, curve 1). This means that there are no redox-isomeric transformations upon formation of such films.

To evaluate the possibility of fixation of the sandwich phthalocyaninate monolayer in a certain redox-isomer state upon its transfer to a solid substrate by the LangmuirBlodgett technique, single-layer $\mathrm{LB}$ films of $\mathrm{Yb}\left[(\mathrm{BuO})_{8} \mathrm{Pc}\right]_{2}$ were formed on thin quartz plates. By analogy with the $\mathrm{Eu}\left[(\mathrm{BuO})_{8} \mathrm{Pc}_{2}\right.$ complex [23], the LB films were transferred at two different values of surface pressure corresponding to two characteristic Q-band positions in the monolayer spectrum. The positions of the $\mathrm{Q}$ and BV bands of the complex in the absorption spectra of the studied samples testify to the conservation of the valence state of the ytterbium ion after the transfer process (Figure 12, curves 2 and 3). It should 
be noted that the position of the $Q$ band in the spectrum of the LB film transferred from the monolayer compressed to a high surface pressure is the same as its position in the spectrum of the solution, which indicates the predominant presence of the metal center in these films in the trivalent state. At the same time, the $Q$ band in the spectrum of the LB film transferred from the monolayer at low surface pressure indicates the predominant presence of the divalent $\mathrm{Yb}$ cations in these films.

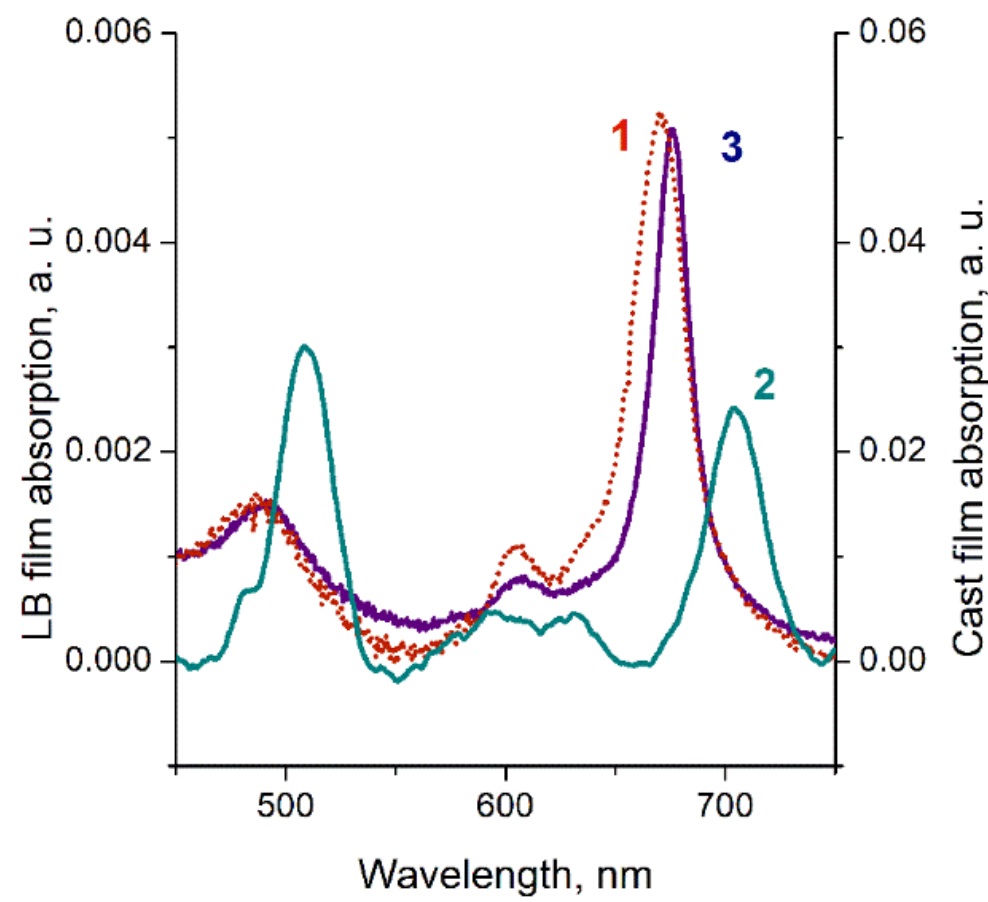

Figure 12. UV-Vis absorbance spectra of $\mathrm{Yb}\left[(\mathrm{BuO})_{8} \mathrm{Pc}_{2}\right.$ of (1) cast film, (2) LB film, transferred from the monolayer formed at low surface pressure, and (3) LB film, transferred from the monolayer compressed to surface pressure of $25 \mathrm{mN} / \mathrm{m}$ where the metal center is in trivalent state.

The film of butoxysubstituted ytterbium bis-phthalocyaninate containing the metal center in the divalent state retains this redox-isomer state of the complex for about four weeks. However, after a long period of time, the spectrum of the studied film returns to the form corresponding to the more stable trivalent state of the ytterbium cation.

It should be emphasized that the described spectral transitions for LB films were reproducibly observed in several independent experiments. Moreover, the very fact of the reported spectral changes of LB films with the divalent metal center in the absence of reducing agents provides additional evidence for the occurrence of the redox-isomer transformation.

\section{Conclusions}

Thus, it has been shown for several trivalent representatives of the lanthanide series that when their donor-substituted bis-phthalocyaninates complexes are deposited onto an aqueous subphase, intramolecular electron transfer from the phthalocyanine ligand to the central metal ion occurs: $\left[\mathrm{Ln}^{3+}\left(\mathrm{R}_{4} \mathrm{Pc}^{2-}\right)\left(\mathrm{R}_{4} \mathrm{Pc}^{\bullet-}\right)\right]^{0} \rightarrow\left[\mathrm{Ln}^{2+}\left(\mathrm{R}_{4} \mathrm{Pc}^{\bullet-}\right)_{2}\right]^{0}$, and upon compression of the monolayer to high surface pressures, a reverse redox-isomeric transformation is observed in most cases. It has been demonstrated that when monolayers of bis-phthalocyaninates of lanthanides with variable valence are transferred to solid substrates, the valence state of the metal center, and consequently, the redox-isomeric state of the complex, do not change. Therefore, this means that we have the possibility to form films with a predefined state of the complex. It should be noted that the redox-isomeric state is expected to affect the entire gamut of physicochemical properties of such films. 
The possibility of the described transformations is determined by the multistability of the bis-phthalocyanine ligand with donor substituents surrounding the lanthanide cations and by the asymmetric position of the complex molecules at the air/water interface. The identification of ways to control this process and knowledge of the properties of the redox isomers themselves will open new prospects for the use of ultrathin films based on these compounds when creating nanoscale information devices.

Supplementary Materials: The following supporting information can be downloaded at: https: / / www.mdpi.com/article/10.3390/sym14020340/s1, MALDI-TOF mass spectral characterization of lanthanide bis-phthalocyaninates: Figure S1. MALDI-TOF mass spectrum of $\mathrm{Sm}\left[(\mathrm{BuO})_{8} \mathrm{Pc}\right]_{2}$; Figure S2. MALDI-TOF mass spectrum of $\operatorname{Er}\left[(\mathrm{BuO})_{8} \mathrm{Pc}_{2} ;\right.$ Figure S3. MALDI-TOF mass spectrum of $\mathrm{Tm}\left[(\mathrm{BuO})_{8} \mathrm{Pc}_{2} ;\right.$ Figure S4. MALDI-TOF mass spectrum of $\mathrm{Yb}\left[(\mathrm{BuO})_{8} \mathrm{Pc}\right]_{2} ;$ Figure S5. MALDI-TOF mass spectrum of $\mathrm{Sm}\left[(15 \mathrm{C} 5)_{4} \mathrm{Pc}\right]_{2}$.

Author Contributions: Conceptualization, A.V.S. and S.L.S.; formal analysis, A.V.S., A.G.M. and S.L.S.; funding acquisition, Y.G.G.; investigation, D.S.K., A.G.M. and A.V.Y.; project administration, Y.G.G.; supervision, A.V.S. and V.V.A.; visualization, D.S.K. and A.G.M.; writing-original draft, D.S.K., A.G.M. and S.L.S.; writing-review and editing, V.V.A. and Y.G.G. All authors have read and agreed to the published version of the manuscript.

Funding: This work was supported by Russian Science Foundation project no. 19-73-20236. This work was partially funded by the Ministry of Science and Higher Education of the Russian Federation (synthesis and characterization of phthalocyanines).

Data Availability Statement: The data presented in this study are available on request from the corresponding authors. The data are not publicly available due to the conditions of the funding body.

Acknowledgments: Part of the experimental study was carried out using the equipment of the IPCE RAS collective use center.

Conflicts of Interest: The authors declare no conflict of interest.

\section{References}

1. Nicoli, F.; Paltrinieri, E.; Tranfić Bakić, M.; Baroncini, M.; Silvi, S.; Credi, A. Binary logic operations with artificial molecular machines. Coord. Chem. Rev. 2021, 428, 213589. [CrossRef]

2. Tasbas, M.N.; Sahin, E.; Erbas-Cakmak, S. Bio-inspired molecular machines and their biological applications. Coord. Chem. Rev. 2021, 443, 214039. [CrossRef]

3. Andreoni, L.; Baroncini, M.; Groppi, J.; Silvi, S.; Taticchi, C.; Credi, A. Photochemical Energy Conversion with Artificial Molecular Machines. Energy Fuels 2021, 35, 18900-18914. [CrossRef]

4. $\quad$ Feng, Y.; Ovalle, M.; Seale, J.S.W.; Lee, C.K.; Kim, D.J.; Astumian, R.D.; Stoddart, J.F. Molecular Pumps and Motors. J. Am. Chem. Soc. 2021, 143, 5569-5591. [CrossRef] [PubMed]

5. Martynov, A.G.; Safonova, E.A.; Tsivadze, A.Y.; Gorbunova, Y.G. Functional molecular switches involving tetrapyrrolic macrocycles. Coord. Chem. Rev. 2019, 387, 325-347. [CrossRef]

6. Kutsybala, D.S.; Shokurov, A.V.; Selektor, S.L. Molecular Machines in 3D and 2D Systems: Movement, Mechanical Work, and Switching. A Review. Prot. Met. Phys. Chem. Surf. 2021, 57, 917-942. [CrossRef]

7. Guda, A.A.; Chegerev, M.; Starikov, A.G.; Vlasenko, V.G.; Zolotukhin, A.A.; Bubnov, M.P.; Cherkasov, V.K.; Shapovalov, V.V.; Rusalev, Y.V.; Tereshchenko, A.A.; et al. Valence tautomeric transition of bis(o-dioxolene) cobalt complex in solid state and solution. J. Phys. Condens. Matter 2021, 33, 215405. [CrossRef]

8. Zolotukhin, A.A.; Bubnov, M.P.; Arapova, A.V.; Fukin, G.K.; Rumyantcev, R.V.; Bogomyakov, A.S.; Knyazev, A.V.; Cherkasov, V.K. Valence-Tautomeric Interconversion in a Bis(dioxolene)cobalt Complex with Iminopyridine Functionalized by a TEMPO Moiety. Phase Transition Coupled with Monocrystal Destruction. Inorg. Chem. 2017, 56, 14751-14754. [CrossRef]

9. Chegerev, M.G.; Piskunov, A.V.; Starikova, A.A.; Kubrin, S.P.; Fukin, G.K.; Cherkasov, V.K.; Abakumov, G.A. Redox Isomerism in Main-Group Chemistry: Tin Complex with o-Iminoquinone Ligands. Eur. J. Inorg. Chem. 2018, 2018, 1087-1092. [CrossRef]

10. Creutz, C.; Taube, H. Direct approach to measuring the Franck-Condon barrier to electron transfer between metal ions. J. Am. Chem. Soc. 1969, 91, 3988-3989. [CrossRef]

11. Buchanan, R.M.; Pierpont, C.G. Tautomeric catecholate-semiquinone interconversion via metal-ligand electron transfer. Structural, spectral, and magnetic properties of (3,5-di-tert-butylcatecholato)(3,5-di-tert-butylsemiquinone)(bipyridyl)cobalt(III), a complex containing mixed-valence. J. Am. Chem. Soc. 1980, 102, 4951-4957. [CrossRef]

12. Pierpont, C.G. Studies on charge distribution and valence tautomerism in transition metal complexes of catecholate and semiquinonate ligands. Coord. Chem. Rev. 2001, 216-217, 99-125. [CrossRef] 
13. Abakumov, G.A.; Cherkasov, V.K.; Nevodchikov, V.I.; Kuropatov, V.A.; Yee, G.T.; Pierpont, C.G. Magnetic properties and redox isomerism for 4,4'-bis(semiquinone) complexes of copper. Inorg. Chem. 2001, 40, 2434-2436. [CrossRef] [PubMed]

14. Nitahara, S.; Akiyama, T.; Inoue, S.; Yamada, S. A photoelectronic switching device using a mixed self-assembled monolayer. J. Phys. Chem. B 2005, 109, 3944-3948. [CrossRef]

15. Poneti, G.; Mannini, M.; Sorace, L.; Sainctavit, P.; Arrio, M.-A.; Otero, E.; Cezar, J.C.; Dei, A. Soft-X-ray-induced redox isomerism in a cobalt dioxolene complex. Angew. Chem. 2010, 49, 1954-1957. [CrossRef]

16. Gütlich, P.; Gaspar, A.B.; Ksenofontov, V.; Garcia, Y. Pressure effect studies in molecular magnetism. J. Phys. Condens. Matter 2004, 16, S1087-S1108. [CrossRef]

17. Roux, C.; Adams, D.M.; Itié, J.P.; Polian, A.; Hendrickson, D.N.; Verdaguer, M. Pressure-Induced Valence Tautomerism in Cobalt o-Quinone Complexes: An X-ray Absorption Study of the Low-Spin [Co III (3,5-DTBSQ)(3,5-DTBCat)(phen)] to High-Spin [Co II (3,5-DTBSQ) 2 (phen)] Interconversion. Inorg. Chem. 1996, 35, 2846-2852. [CrossRef]

18. Caneschi, A.; Dei, A.; de Biani, F.F.; Gütlich, P.; Ksenofontov, V.; Levchenko, G.; Hoefer, A.; Renz, F. Pressure- and TemperatureInduced Valence Tautomeric Interconversion in ao-Dioxolene Adduct of a Cobalt-Tetraazamacrocycle Complex. Chem.-A Eur. J. 2001, 7, 3926-3930. [CrossRef]

19. Deal, A.M.; Rapf, R.J.; Vaida, V. Water-Air Interfaces as Environments to Address the Water Paradox in Prebiotic Chemistry: A Physical Chemistry Perspective. J. Phys. Chem. A 2021, 125, 4929-4942. [CrossRef]

20. Shokurov, A.V.; Kutsybala, D.S.; Kroitor, A.P.; Dmitrienko, A.A.; Martynov, A.G.; Enakieva, Y.Y.; Tsivadze, A.Y.; Selektor, S.L.; Gorbunova, Y.G. Spin Crossover in Nickel(II) Tetraphenylporphyrinate via Forced Axial Coordination at the Air/Water Interface. Molecules 2021, 26, 4155. [CrossRef]

21. Zhao, W.; Tong, B.; Pan, Y.; Shen, J.; Zhi, J.; Shi, J.; Dong, Y. Fabrication, electrochemical, and optoelectronic properties of layer-by-layer films based on (phthalocyaninato)ruthenium(II) and triruthenium dodecacarbonyl bridged by 4,4'-bipyridine as ligand. Langmuir 2009, 25, 11796-11801. [CrossRef]

22. Selektor, S.L.S.L.; Shokurov, A.V.; Arslanov, V.V.; Gorbunova, Y.G.; Birin, K.P.; Raitman, O.A.; Morote, F.; Cohen-Bouhacina, T.; Grauby-Heywang, C.; Tsivadze, A.Y. Orientation-Induced Redox Isomerism in Planar Supramolecular Systems. J. Phys. Chem. C 2014, 118, 4250-4258. [CrossRef]

23. Shokurov, A.V.; Kutsybala, D.S.; Martynov, A.G.; Bakirov, A.V.; Shcherbina, M.A.; Chvalun, S.N.; Gorbunova, Y.G.; Tsivadze, A.Y.; Zaytseva, A.V. Long-Sought Redox Isomerization of the Europium(III/II) Complex Achieved by Molecular Reorientation at the Interface. Langmuir 2020, 36, 1423-1429. [CrossRef] [PubMed]

24. Tezgerevska, T.; Alley, K.G.; Boskovic, C. Valence tautomerism in metal complexes: Stimulated and reversible intramolecular electron transfer between metal centers and organic ligands. Coord. Chem. Rev. 2014, 268, 23-40. [CrossRef]

25. Drath, O.; Boskovic, C. Switchable cobalt coordination polymers: Spin crossover and valence tautomerism. Coord. Chem. Rev. 2018, 375, 256-266. [CrossRef]

26. Fedushkin, I.L.; Maslova, O.V.; Baranov, E.V.; Shavyrin, A.S. Redox Isomerism in the Lanthanide Complex [(dpp-Bian)Yb(DME)( $\mu$ Br)] 2 (dpp-Bian = 1,2-Bis[(2,6-diisopropylphenyl)imino]acenaphthene). Inorg. Chem. 2009, 48, 2355-2357. [CrossRef]

27. Fedushkin, I.L.; Maslova, O.V.; Morozov, A.G.; Dechert, S.; Demeshko, S.; Meyer, F. Genuine redox isomerism in a rare-earth-metal complex. Angew. Chem. Int. Ed. 2012, 51, 10584-10587. [CrossRef] [PubMed]

28. Ishikawa, N.; Ohno, O.; Kaizu, Y. Electronic states of bis(phthalocyaninato)lutetium radical and its related compounds: The application of localized orbital basis set to open-shell phthalocyanine dimers. J. Phys. Chem. 1993, 97, 1004-1010. [CrossRef]

29. Shokurov, A.V.; Kutsybala, D.S.; Martynov, A.G.; Yagodin, A.V.; Gorbunova, Y.G.; Novikov, D.; Bakirov, A.V.; Shcherbina, M.A.; Chvalun, S.N.; Arslanov, V.V.; et al. Fluorescence Mode XANES Spectroscopy as a Powerful Tool for Redox-Isomerism Studies in Ultrathin Films. Macroheterocycles 2019, 12, 264-267. [CrossRef]

30. Stuchebryukov, S.D.; Selektor, S.L.; Silantieva, D.A.; Shokurov, A.V. Peculiarities of the reflection-absorption and transmission spectra of ultrathin films under normal incidence of light. Prot. Met. Phys. Chem. Surf. 2013, 49, 189-197. [CrossRef]

31. Martynov, A.G.; Berezhnoy, G.S.; Safonova, E.A.; Polovkova, M.A.; Gorbunova, Y.G.; Tsivadze, A.Y. Aromatic Nucleophilic Substitution as a Side Process in the Synthesis of Alkoxy- and Crown-Substituted (Na)phthalocyanines. Macroheterocycles 2019, 12, 75-81. [CrossRef]

32. Oluwole, D.O.; Yagodin, A.V.; Mkhize, N.C.; Sekhosana, K.E.; Martynov, A.G.; Gorbunova, Y.G.; Tsivadze, A.Y.; Nyokong, T. First Example of Nonlinear Optical Materials Based on Nanoconjugates of Sandwich Phthalocyanines with Quantum Dots. Chem. Eur. J. 2017, 23, 2820-2830. [CrossRef]

33. Takahashi, K.; Tomita, Y.; Hada, Y.; Tsubota, K.; Handa, M.; Kasuga, K.; Sogabe, K.; Tokii, T. Preparation and Electrochemical Properties of the Green Ytterbium(III) and Lutetium(III) Sandwich Complexes of Octabutoxy-Substituted Phthalocyanine. Chem. Lett. 1992, 759-762. [CrossRef]

34. Nefedova, I.V.; Gorbunova, Y.G.; Sakharov, S.G.; Tsivadze, A.Y. Synthesis and spectroscopic study of terbium (III) and neodymium (III) complexes with tetra-15-crown-5-phthalocyanine. Russ. J. Inorg. Chem. 2005, 50, 165-173.

35. Markovitsi, D.; Tran-Thi, T.-H.; Even, R.; Simon, J. Near infrared absorption spectra of lanthanide bis-phthalocyanines. Chem. Phys. Lett. 1987, 137, 107-112. [CrossRef]

36. Rousseau, R.; Aroca, R.; Rodríguez-Méndez, M.L. Extended Hückel molecular orbital model for lanthanide bisphthalocyanine complexes. J. Mol. Struct. 1995, 356, 49-62. [CrossRef] 
37. May, A.; Majumdar, P.; Martynov, A.G.; Lapkina, L.A.; Troyanov, S.I.; Gorbunova, Y.G.; Tsivadze, A.Y.; Mack, J.; Nyokong, T. Optical limiting properties, structure and simplified TD-DFT calculations of scandium tetra-15-crown-5 phthalocyaninates. $J$. Porphyr. Phthalocyanines 2020, 24, 589-601. [CrossRef]

38. Gorbunova, Y.G.; Rodríguez-Méndez, M.L.; Kalashnikova, I.P.; Tomilova, L.G.; de Saja, J.A.; Rodríguez-Morgade, M.S. Langmuir-Blodgett Films of Bis(octakispropyloxy) Samarium Bisphthalocyanine. Spectroscopic and Gas-Sensing Properties. Langmuir 2001, 17, 5004-5010. [CrossRef]

39. Shokurov, A.V.; Kutsybala, D.S.S.; Martynov, A.G.; Raitman, O.A.A.; Arslanov, V.V.V.; Gorbunova, Y.G.G.; Tsivadze, A.Y.; Selektor, S.L.L. Modulation of transversal conductivity of europium(III) bisphthalocyaninate ultrathin films by peripheral substitution. Thin Solid Film. 2019, 692, 137591. [CrossRef]

40. Ayhan, M.M.; Singh, A.; Jeanneau, E.; Ahsen, V.; Zyss, J.; Ledoux-Rak, I.; Gürek, A.G.; Hirel, C.; Bretonnière, Y.; Andraud, C. ABAB Homoleptic Bis(phthalocyaninato)lanthanide(III) Complexes: Original Octupolar Design Leading to Giant Quadratic Hyperpolarizability. Inorg. Chem. 2014, 53, 4359-4370. [CrossRef] [PubMed] 